\title{
Ultrasound-assisted synthesis of aliphatic acid esters at room temperature
}

\author{
Cristiane B. Hobuss ${ }^{a}$, Bruna S. Pacheco ${ }^{a}$, Alexander O. Souza ${ }^{a}$, Marina Ritter ${ }^{a}$, Marco \\ A. Z. Santos ${ }^{\mathrm{a}}$, José C. Campos ${ }^{\mathrm{a}}$, Frank H. Quina ${ }^{\mathrm{b}}$ and Claudio M. P. Pereira ${ }^{\mathrm{a}^{*}}$ \\ aUniversidade Federal de Pelotas, Centro de Ciências Químicas, Farmacêuticas e de Alimentos, 96010-900, \\ Pelotas, RS, Brazil \\ ${ }^{b}$ Universidade de São Paulo, Instituto de Química, 05513-970, São Paulo, RS, Brazil \\ *claudio.martin@pq.cnpq.br and claudiochemistry@gmail.com.
}

Keywords: Ultrasound irradiation, aliphatic esters, sonochemistry

\section{INTRODUCTION}

Fatty acid esters and derivatives find widespread applications in the food, cosmetics and pharmaceutical industries owing to their biodegradability and low toxicity. Esters of short chain fatty acids are important flavor and aroma compounds and esters of long chain fatty acids are being explored for their use as biodiesel and as waxes in the oleo-chemical industries. ${ }^{1}$

The favorable effects of ultrasonic irradiation are playing an increasing role in chemical processes, especially in cases where classical methods require onerous conditions or prolonged reaction times. As part of our continuing work on the use of ultrasound irradiation to improve organic reactions, we report here a rapid and facile procedure for the synthesis of saturated aliphatic acid esters by the ultrasound irradiation induced reaction of aliphatic acids with methanol or ethanol in acidic media at room temperature. $^{2}$

\section{RESULTS AND DISCUSSION}

The procedure reported here is quite simple. The esters were prepared by esterification of the fatty acid, 1, with ethanol or methanol in the presence of sulfuric acid $(20 \%)$ under ultrasonic irradiation $(20$ $\mathrm{kHz}$ ) for 15-30 min at room temperature Scheme 1, In comparison with conventional methods described in the literature, the principal advantages of our procedure are the significant decrease in the reaction time (just 15-30 min are required) and the temperature (room temperature) with no sacrifice in the product yields (70-95\%) Table 1.

Scheme 1. Synthesis of aliphatic acid esters

$$
\begin{aligned}
& \mathrm{R}_{1} \mathrm{COOH}+\mathrm{R}_{2} \mathrm{OH} \stackrel{\text { i. }}{\rightleftharpoons} \mathrm{R}_{1} \mathrm{COOR}+\mathrm{H}_{2} \mathrm{O}
\end{aligned}
$$

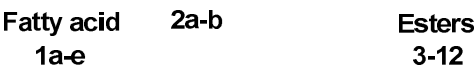

$$
\begin{aligned}
& \text { i. } \mathrm{H}_{2} \mathrm{SO}_{4} \\
& \mathrm{R}_{1}: \mathrm{C}_{7} \mathrm{H}_{16}, \mathrm{C}_{9} \mathrm{H}_{20}, \mathrm{C}_{11} \mathrm{H}_{24}, \mathrm{C}_{13} \mathrm{H}_{28}, \mathrm{C}_{15} \mathrm{H}_{32} \\
& \mathrm{R}_{2}: \mathrm{CH}_{3}, \mathrm{CH}_{3} \mathrm{CH}_{2}
\end{aligned}
$$

Table 1. Ultrasound-assisted ester syntesis

\begin{tabular}{ccccccc}
\hline & Product & & \multicolumn{2}{c}{ Sonochemistry } & \multicolumn{2}{c}{ Literature $^{3-4}$} \\
\cline { 3 - 7 } Ester & $\mathrm{R}_{1}$ & $\mathrm{R}_{2}$ & $\begin{array}{c}\text { Time } \\
\text { (min.) }\end{array}$ & $\begin{array}{c}\text { Yield } \\
(\%)\end{array}$ & $\begin{array}{c}\text { Time } \\
(\text { h. })\end{array}$ & $\begin{array}{c}\text { Yield } \\
(\%)\end{array}$ \\
\hline $\mathbf{3}$ & $\mathrm{C}_{7} \mathrm{H}_{16}$ & $\mathrm{CH}_{3}$ & 30 & 93 & 21 & 73 \\
$\mathbf{4}$ & $\mathrm{C}_{9} \mathrm{H}_{20}$ & $\mathrm{CH}_{3}$ & 15 & 80 & 48 & 64 \\
$\mathbf{1 0}$ & $\mathrm{C}_{11} \mathrm{H}_{24}$ & $\mathrm{CH}_{3} \mathrm{CH}_{2}$ & 15 & 70 & 6 & 65 \\
$\mathbf{1 2}$ & $\mathrm{C}_{7} \mathrm{H}_{16}$ & $\mathrm{CH}_{3} \mathrm{CH}_{2}$ & 30 & 95 & 3.5 & 95 \\
\hline
\end{tabular}

*Yields of isolated products.

\section{CONCLUSION}

The procedure described here is an economical and efficient method for carrying out esterification reactions of commercial importance. Significant advantages of the method include the fact that: (i) the reaction is simple to execute; (ii) the reaction can be conducted at ambient temperature; (iii) the required reaction times are short (15-30 min.); (iv) the workup is very simple; and (v) the products are isolated in good yields (70-95\%). This mild, convenient and improved protocol for the ultrasound-promoted preparation of esters can potentially be explored for biodiesel synthesis.

\section{ACKNOWLEDGEMENTS}

The authors are grateful to UFPel, INCT de Estudos do Meio Ambiente (573.667/2008-0), CEPEMA-USP (Centro de Capacitação e Pesquisa em Meio Ambiente), CNPq (310472/2007-5, 475575/2008-3), FAPERGS and CAPES for financial and fellowship support. FHQ is affiliated with the INCT for Catalysis in Molecular and Nanostructures Systems (INCTCatalysis).

\section{REFERENCES}

${ }^{1}$ Saxena, R.K; Ghosh, P.K.; Gupta, R.; Davidson, W.S.; Bradoo, S.; Gulati, R., Curr. Sci. 1999, 77, 101.

${ }^{2}$ Pizzuti, L.; Piovesan, L.A.; Flores, A.F.C; Quina, F.H; Pereira, C.M.P., Ultrason. Sonochem. 2009, 16, 728.

${ }^{3} \mathrm{Li}, \mathrm{X}$.; Eli, W., J. Mol. Catal. A. Chem. 2008, 279, 159.

${ }^{4} \mathrm{Li}$, C.; Yang, J.; Wang, P.; Liu, J.; Yang, Q., Microporous Mesoporous Mater 2009, 123, 228.

Ultrasonics Sonochem., 2011, in press.

$14^{\text {th }}$ Brazilian Meeting on Organic Synthesis $-14^{\text {th }}$ BMOS - September 01-05, 2011-Brasilia, Brazil 